\title{
Managing data on construction techniques and damage using digital media
}

\author{
X. Romão ${ }^{1}$, E. Paupério ${ }^{2}$, A. Costa ${ }^{3}$ \\ ${ }^{1}$ Departamento de Engenharia Civil, Faculdade de Engenharia da Universidade do Porto, Porto, Portugal \\ ${ }^{2}$ Instituto da Construção, Faculdade de Engenharia da Universidade do Porto, Porto, Portugal \\ ${ }^{3}$ Universidade de Aveiro, Porto, Portugal
}

\begin{abstract}
Sustainable management and conservation strategies for constructions are known to be highly dependent on the availability of adequate documentation and recordings of relevant data, namely about the structural conditions and the materials of the construction. Available digital technologies have been changing the recording practice by offering new tools to collect, analyse and disseminate information about existing constructions. In this context, the role of GIS-based tools and multimedia technologies in managing and presenting information on existing constructions is addressed herein.
\end{abstract}

\section{INTRODUCTION}

The traditional constructions of a country, as an essential part of its historical and cultural identity, need to be preserved. The development of sustainable management and conservation strategies for such constructions are seen to be highly dependent on the availability of adequate documentation and recordings of relevant data, namely about their structural conditions and the construction materials. Hence, the technical survey of a construction must involve appropriate information identification and acquisition techniques capable of producing useful data that will enable the technicians to understand the construction and its context with the necessary precision.

Available digital technologies have been changing the recording practice by offering new tools to collect, analyse and disseminate information about the constructions (Eppich, 2011; Letellier, 2011;). Therefore, one can expect the amount and the type of recorded information to have the tendency to increase. This fact leads to the need for adequate systems enabling an efficient management of such information. In this context, the development of recording tools based on geographical information systems (GIS) has been taking a leading role given their advantages, especially in areas where spatial and/or geographical data analysis is fundamental. In the field of construction-related data recording and management, the usefulness of GIS-based tools is related to their versatility to enable the manipulation, analysis, recording and mapping of large amounts of data. As an example of this type of approach, a GISbased tool recently developed for the recording and management of construction data is presented herein.
The conservation of existing constructions asks for an integrated methodology that includes the steps of Analysis (which involves the technical survey), Diagnosis, Therapy and Control (Searls et al, 1997). The Analysis and Diagnosis phases are essential for the definition of a correct intervention, both in terms of the technologies and materials that are better suited to the characteristics of the construction. Therefore, the sustainable rehabilitation of a construction, accounting for its architectural, historical and constructive values, must involve carefully developed Analysis and Diagnosis steps. The results obtained from these two steps are usually presented in a written technical report, which is the fundamental asset supporting the intervention (Therapy and Control) options. This report not only serves as the input and justification for the decisions that have to be made in terms of the rehabilitation process, but it is also an archive of information about the construction that might be needed in future studies.

Since conservation/rehabilitation projects normally involve a multidisciplinary team of technicians, this report needs to highlight the different approaches and interests of each area of expertise. The main drawback of this approach, as an information presentation tool, is that multidisciplinary reports presenting information on a vast number of areas of expertise are becoming less practical due to the large amount of information they contain. In such cases, each technician chooses to consult only the information directly addressing its area of expertise, thus missing out on the comprehensive multidisciplinary conservation/rehabilitation approach.

In order to address these issues, complementary means of information and knowledge presentation 
are also presented herein. The proposed examples involve data representations that are not easily introduced, or are simply unable to be included, in a classical written report format. Nonetheless, it should be emphasized that such new means of data presentation serve only as a complement to the written report and not as its replacement. Regarding the presented examples, most of the survey procedures involved were visual assessments and geometric data was obtained by hand surveys. Drill holes and non destructive tests were also used to determine material properties when need. A detailed presentation of such procedures is not addressed herein since the focus of the proposed paper deals mainly with the advantages of using digital media to present the recorded data. The proposed examples are based on the survey of two houses located in different Portuguese cities. Both constructions are representative of typical wealthy houses and, despite the formal nature of their architectural characteristics, their building materials and techniques are considered to fall within the conceptual principles of vernacular architecture. To illustrate these aspects, one of the selected houses, which is located in Vila do Conde, is shown in figure 1a) in its current urban environment while figure 1b) presents a postcard of the house in the XIX $^{\text {th }}$ century settlement that highlights the local features of its architectural characteristics.
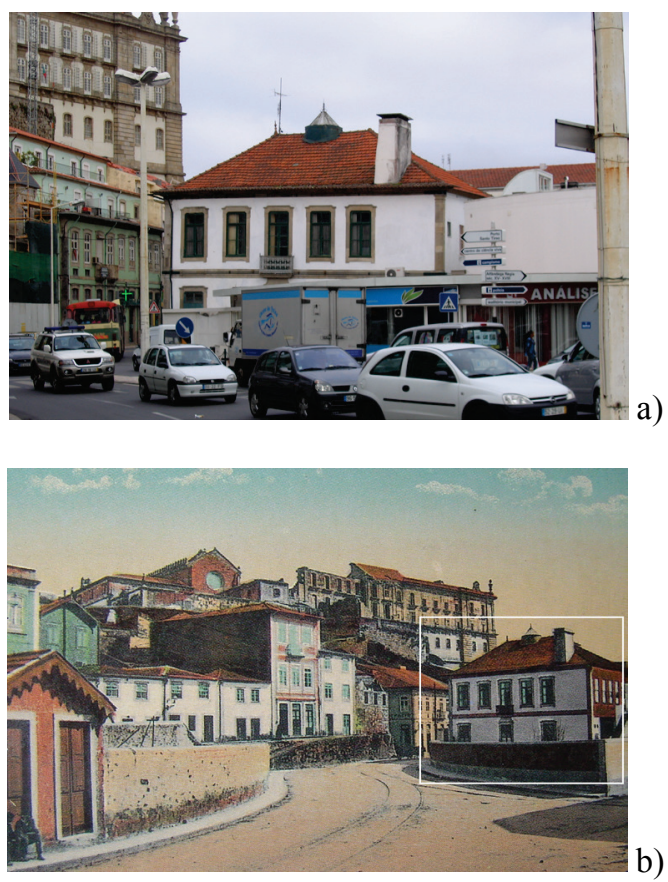

Figure 1. Current urban view of the Vila do Conde house (a) and $\mathrm{XIX}^{\text {th }}$ cent. postcard view (b). (Photo credits: Pauperio, E.).

\section{GIS-BASED RECORDING OF CONSTRUCTION-RELATED DATA}

\subsection{Description of the proposed GIS-based tool}

To help in the recording and management of data obtained during the technical survey of an existing con- struction, a GIS-based tool was developed by the Construction Institute of the Faculty of Engineering of the University of Porto. This tool, called SIMDE (System of Inventory for Materials and Damages in Buildings), figure 2, is an application that runs over the ArcGIS software (ESRI, 2011). SIMDE was developed to enable the recording of detailed information about materials and damages of existing constructions, having in mind both practice-oriented and strategic objectives for the preservation of such constructions. After performing an on-site survey of the data with SIMDE, using a tablet PC, SIMDE enables the automatic definition of customized damage and material maps that use specifically defined symbols for the mapping representations. Besides the technical merits of such graphic representations, these maps also work as efficient visual aids for decision makers. Therefore, SIMDE was developed in order to enable the production of easy-to-read materials and damage maps in a more automatic way. By doing so, it is expected that the information processing time after the on-site recording and survey operations is considerably reduced. Moreover, SIMDE also features the possibility of managing recordings and surveys carried out over different instants in time for the same construction. This feature enables the monitoring of the construction conditions by a direct overlapping of different layers representing the different surveys.

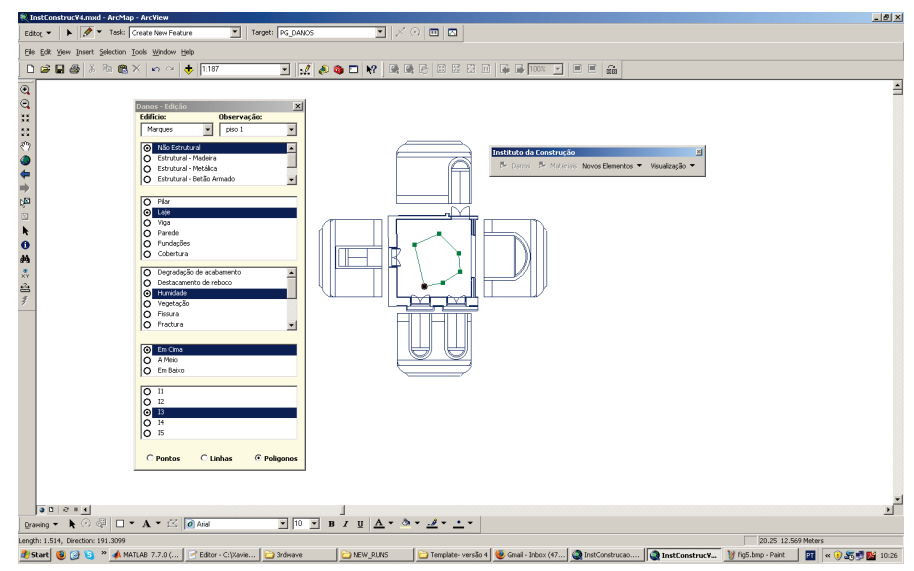

Figure 2. A view of the interface of SIMDE.

Although it is possible to identify several advantages about the use of a tool such as SIMDE, attention is brought to three particular aspects. First, a near $100 \%$ reduction of the information processing time after the on-site survey can be expected since the production of output maps is carried out automatically by SIMDE. Second, the availability of such detailed information about the constructions in an attractive graphical format, including its evolution over time, allows decisions about the need to rehabilitate the construction to be more easily made by decision makers. Third, such information can also be seen to be of extreme value in emergency situations where information about the initial state of a given 
heritage construction is necessary for surveys and condition assessments after an accident (e.g. a fire or an earthquake). Furthermore, in such cases, SIMDE can be used to record the updated state of the construction to be used for posterior safety analyses.

\subsection{Example application of SIMDE}

The example application presented in the following involves the partial survey of a building. The initial survey of the building was carried out using traditional methods. Part of the survey was then repeated using SIMDE to highlight its advantages. Figure 3a) presents a view of the main façade while figure $3 \mathrm{~b}$ ) presents a view of the interior of the selected building, which is a XIX ${ }^{\text {th }}$ century palace located in Porto, Portugal (Costa et al, 2005). The part of the survey that is addressed herein involves the recording of damages to the high-value interior finishes and decorative elements.

Figure 4a) shows the damage map obtained for one of the building rooms using a traditional survey. Each type of damage was recorded using a different terminology and symbol.
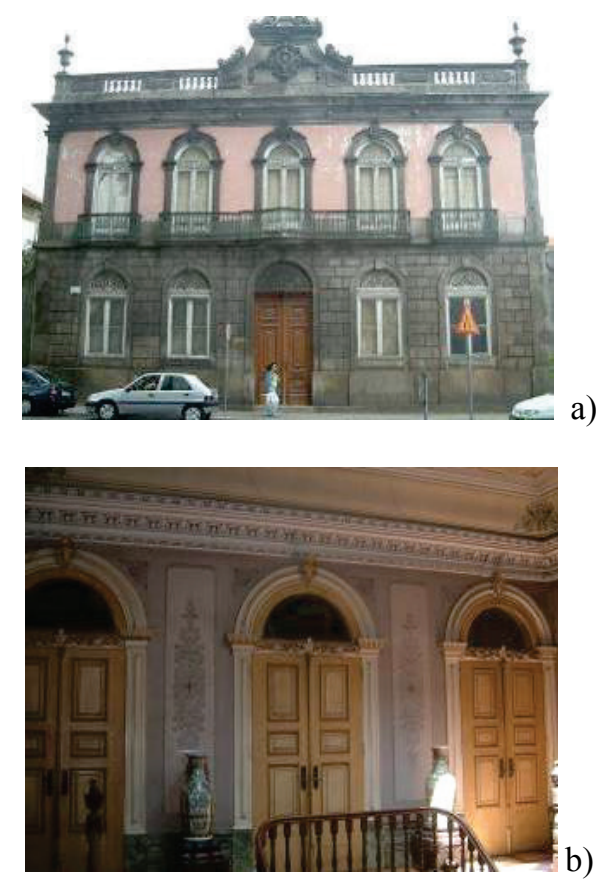

Figure 3. Façade (a) and interior view (b) of the building in Porto. (Photo credits: Pauperio, E.).

The final damage map was prepared using CAD, based on the detailed manual survey carried out insitu using technical drawings. The map colors were defined to enable a clear reading of the damages due to the significant number of damaged areas in each room. The intensity of the damages, however, was not represented. Still, two intensities of cracks were represented (light crack and intense crack), each one with a different symbol.

The survey of this room took two hours and involved two persons. The final damage map in CAD took four more hours to be produced by one person. Figure $4 \mathrm{~b}$ ) shows the damage map of the same room after it was surveyed using SIMDE. Although the insitu survey time was the same, involving also two persons, no further post-processing was needed since SIMDE produces the damages maps automatically. As previously referred, the symbols used in these maps were specifically developed for SIMDE. In these symbols, the different colors refer to the damage intensities, which allow a more clear assessment of the overall state of damage of the room. By comparing the two survey approaches, it becomes clear that SIMDE is more effective, particularly in terms of the time involved to produce the final map.

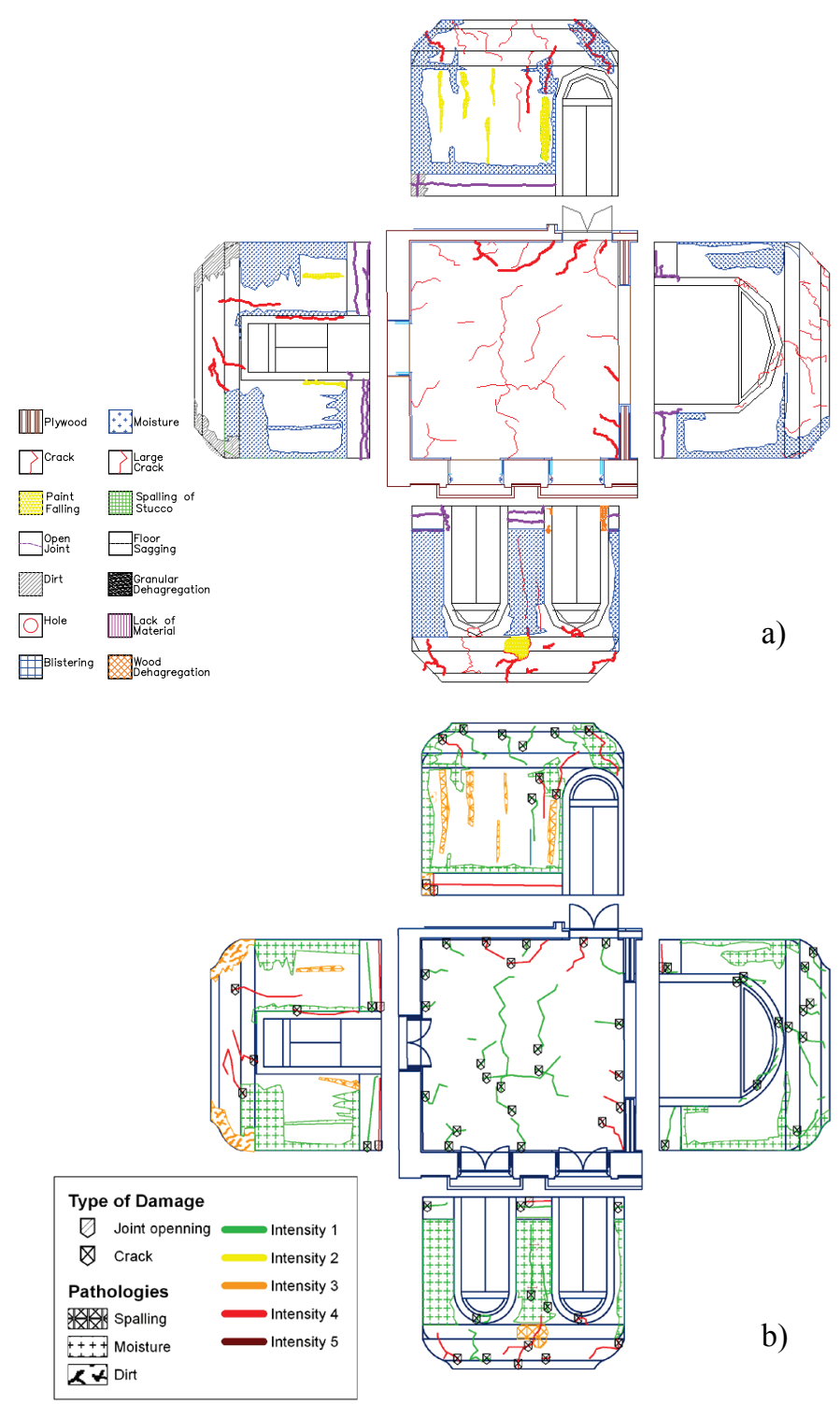

Figure 4. Map of the damages recorded in a room of the building using a traditional survey (a) and using SIMDE (b).

\section{THE NEED FOR THE ADEQUATE DOCUMENTATION AND PRESENTATION OF SURVEY DATA}

Although damage and material maps that can be developed using a GIS-based tool such as SIMDE en- 
hance the readability of the data gathered during the technical survey, there are other aspects of the data obtained from the survey that must be adequately documented and presented. Difficulties in the documentation and presentation of the such data, resulting from the use of inadequate dissemination formats, may be responsible for enhancing the gap between the information users (project managers, planners, politicians and general decision makers) and the information providers (surveyors and specialists of more technical areas of expertise). For the information users, the presented data must remain clear and self-explanatory, and should increase the interest in having this knowledge, thus highlighting the value of the construction and justifying the need for the intervention. Therefore, data documentation and presentation can be seen to be accountable for the successful development of a conservation project at the technical, financial and social levels.

Information identification and acquisition techniques have to meet specific requirements depending on the problem at hand (e.g. a structural stability problem, the deterioration of a stone or adobe surface or the conservation of a wall painting), and will also depend on the size of the construction and on the level of accuracy needed. Nonetheless, one must keep in mind that survey protocols ideal for all circumstances do not exist. Therefore, detailed operative strategies for construction surveys are defined on a case by case approach. Construction survey operations include geometric recordings, damage levels recordings, photographing, in-situ chemical or structural tests on materials and data gathering on the history and present condition of the construction.

Data resulting from the survey must then be organized, harmonized and presented to enable a wellfounded analysis of the construction that will ultimately produce a Diagnosis about the state of the construction. In most cases, the information is presented using a self-contained written report containing the full range of information related to the different areas of expertise. Since conservation projects normally involve a multidisciplinary team of technicians, the preparation of this report contributes to the conciliation of the different areas of intervention. For example, engineers must be aware that a particular wall that needs to be retrofitted has a finishing that must be preserved (e.g. paintings), while conservators/restorers should know that the referred finishing is part of a wall that will be retrofitted. As previously referred, the main disadvantage of this approach as a data presentation tool is that multidisciplinary reports presenting information on a vast number of areas of expertise are not always practical due to the large amount of information they contain. Common problems with classical written reports range from fluidity and transparency of information communication, misleading interpretation of technical data and poor interdisciplinary collaboration.
Therefore, such reports are reckoned to fall short in presenting the information in a suitable way and, simultaneously, to be difficult to examine and handle when they include a broad range of information.

\section{MULTIMEDIA FOR CONSTRUCTION CONSERVATION AND REHABILITATION}

In order to address the previously referred data management and presentation issues, the development of complementary means of data presentation are addressed herein. The proposed examples involve data representations that are not easily introduced, or are simply unable to be included, in a classical written report format. These complementary means consist of multimedia modules that can be integrated into multimedia presentations or CD-Roms.

\subsection{Multimedia frameworks types}

Multimedia data presentation frameworks allow data in the form of text, photos or technical drawings to be combined with components having different levels of interactivity. For example, it is possible to develop interactive damage maps allowing interactive switching between schematic representations of the observed damage and real photos of the damage (along with its possible evolution over time) at selected locations. Interactive 3D models of the construction can also be developed. Such models may address the architectural aspects of the construction, the structural aspects, or even both. This type of information presentation enables real-time interaction between the user and the model, allowing the user to move, rotate or zoom the model, to turn on or off the visibility of specific elements of the construction by accessing the model tree hierarchy, to define 3D cross-sections and 3D measurements. Dynamic and interactive linking between different sources of information in the Internet opens a wide range of possibilities and opportunities for information organization and presentation. Finally, movies are another important type of information that can be included in such multimedia platforms. One interesting and useful example of this type of information might be the inclusion of video recordings of tests performed during the structural assessment stage.

\subsection{Examples of multimedia frameworks}

Several examples of multimedia applications that were developed for the presentation of data about a house with interesting structural and architectural features are reported in the following.

The house is located in Vila do Conde, Portugal, and has a ground level, an elevated storey and an attic (figure 5). The particular significance of this house comes from the fact that it represents a rather 
common XIX $^{\text {th }}$ century rural construction of the northern part of Portugal that has undergone little alterations over the time. After carrying out a survey of the construction, it was found that a structural repair and strengthening intervention was required (Costa et al, 2004). The structural rehabilitation was carefully defined in order to minimize the intervention, as suggested in (ICOMOS, 2001). In addition to the fact that the construction has undergone very few alterations with respect to its original form, whether it is in terms of the granite masonry walls, or in terms of the floor and roof timber structures, the finishing techniques of the interior walls also present interesting details. Moreover, some interior architectural elements were also found to add to this interest.

Some of the multimedia frameworks that were developed include global damage maps of the house, pictorial representations of the damages by façade that integrate interactive photos of the real damage (figure 6), an interactive map for the geographical location and the urban surroundings of the house that include photos (figure 7) and digital maps of the finishes of the façades (figure 8).

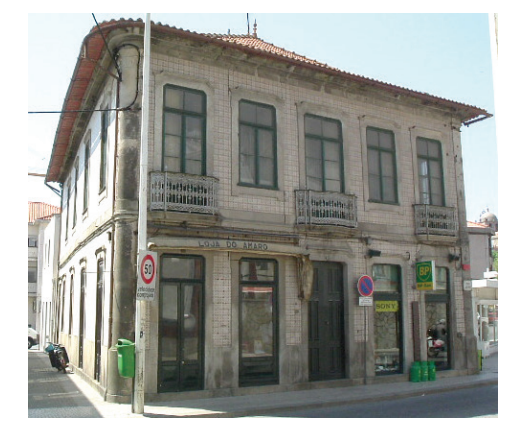

Figure 5. Main façade of the house in Vila do Conde. (Photo credits: Pauperio, E.).

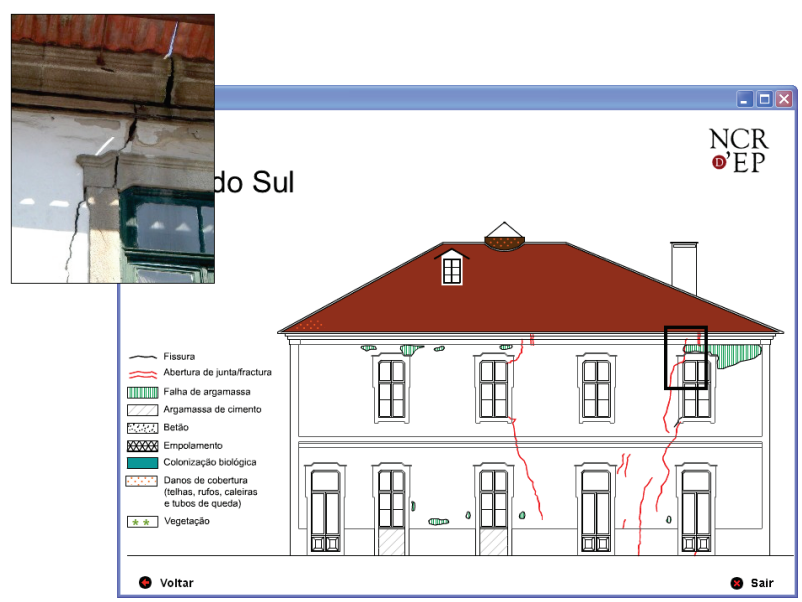

Figure 6. Digital mapping of the damages with interactive display of a structural damage.

A digital library of the techniques of the finishes of the interior walls and ceilings was also developed (figure 9). This library includes descriptions of each technique, obtained from the existing literature (Dias, 1999; Segurado, s.d.; Teixeira e Belêm, 1998) and photos of their application on the house. An in- teractive 3D model of the house was also developed (figures 10 and 11). This model was developed to characterize and define with sufficient precision the structure of the house. However, it also features architectural elements such as interior walls, door and windows. Using this model, it is possible to define dynamic cut-cross sections to view parts of the house, to measure the depth of structural walls, the length of the timber beams of the floors or to visualize the connection points between the different structural elements.

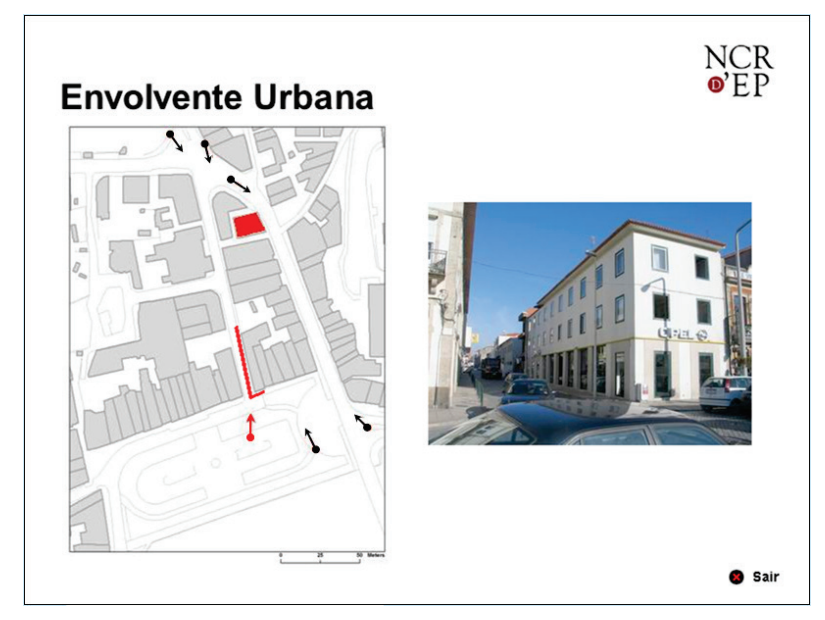

Figure 7. Interactive map of the urban surroundings.

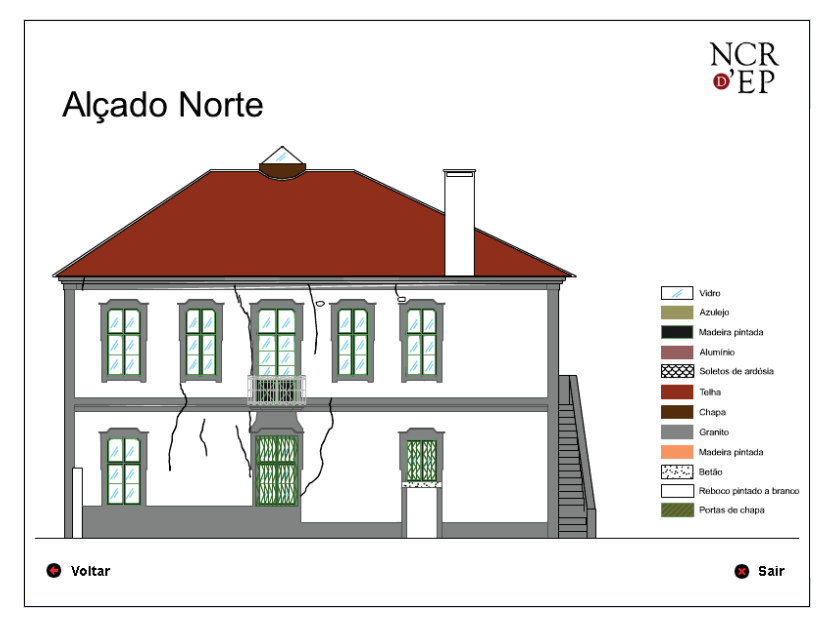

Figure 8. Digital mapping of the exterior finishes.

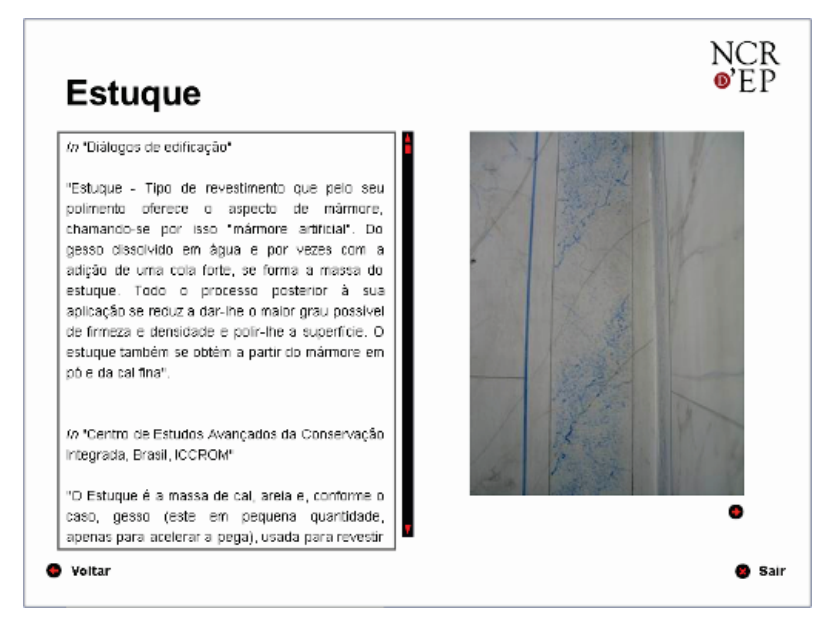

Figure 9. Digital library of the techniques of the finishes of the interior walls and ceilings. 


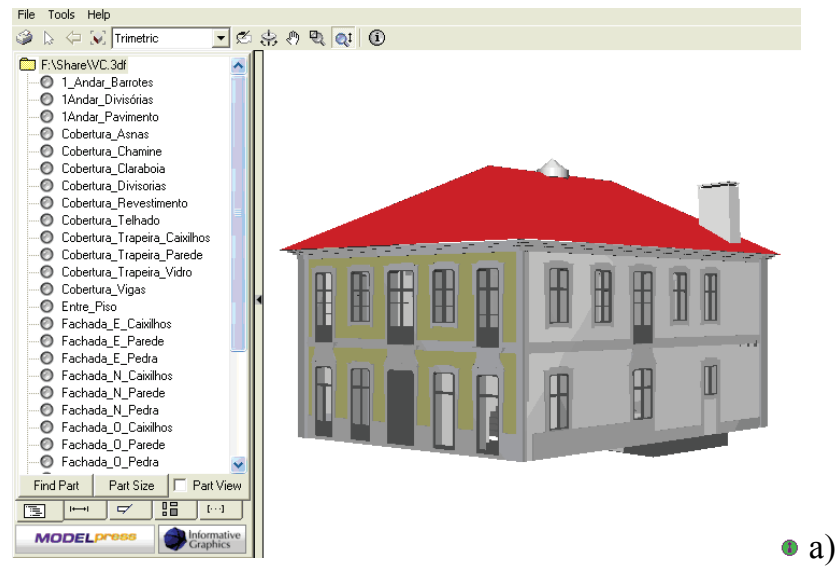

Figure 10. Interactive 3D model of the house: view of the exterior.

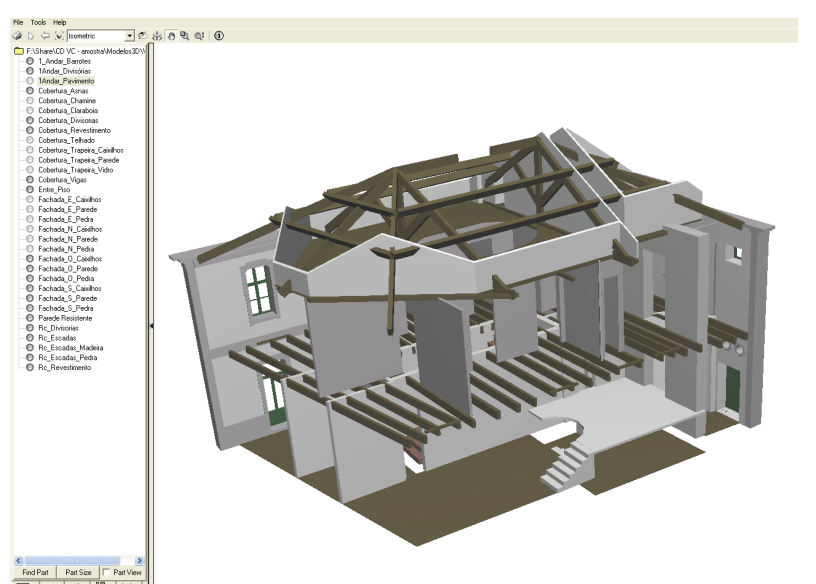

Figure 11. Interactive 3D model of the house: view of the interior.

\section{FINAL REMARKS}

The inventory and management of information about existing constructions have an unquestionable importance in modern society where strategic aspects such as sustainability are critical in the management of the built environment. In this context, the usefulness of tools based on Geographic Information Systems (GIS) is demonstrated by their ability to analyze, handle, store and map large amounts of data.

The proposed paper presented a GIS-based tool called SIMDE that was specifically devised to enable the inventory of materials and damages gathered during the survey of existing buildings. The particular advantages of having such tool were addressed, namely in terms of its higher efficiency when compared to that of traditional survey approaches. An application example was also presented to highlight the referred advantages.

The paper also addressed the use of multimedia techniques for presentation, organization and management of technical information about existing constructions. These multimedia applications are a complement to the technical survey report since they are able to present important information that is dif- ficult to integrate and compile within a text report. Such tools are reckoned to be valuable aids for presenting of different types of information and providing a simple and enlightening way to classify and organize the available data. Moreover, multimedia frameworks enhance and ease the exchange of information between different members of multidisciplinary teams involved in the assessment and rehabilitation of constructions, thus increasing the overall efficiency of the project management.

Examples of such multimedia applications were presented for a case study involving a traditional house. Applications were developed to present information about construction techniques, structural and architectural features, and general/local geographical aspects of the construction. The development of these multimedia applications was found to be an interesting example on how simple multimedia tools and environments can assist in information management and presentation. In sum, information presentation with the aid of such tools is an affordable component of increasing importance within the current information society in which communication and visualization of data are fundamental issues.

\section{REFERENCES}

Costa, A., Guedes, J. M., Paupério, E., Miranda, L., 2004. Relatório de inspecção - Edifício de Vila do Conde. Relatório IC20-RVT43-A-NG54, IC-FEUP.

Costa, A., Guedes, J. M., Paupério, E., Ornelas, C., Ilharco, T., 2005. Relatório de inspecção à Casa Marquês de Pombal n. ${ }^{\circ}$ 30". Relatório OU10-RVT70-A-NG89, IC-FEUP.

Dias, P., 1999. História da arte portuguesa no Mundo (14151822). O espaço atlântico, Círculo de Leitores, Lisboa.

ESRI, 2011. ArcGIS Desktop: Release 10. Redlands, CA: Environmental Systems Research Institute.

ICOMOS, 2001. Recommendations for the analysis, conservation and structural restoration of architectural heritage. International Council on Monuments and Sites.

Searls, C., Binda, L., Henriksen, J., Mirwald, P., Nappi, A., Price, C., Van Balen, K., Vergès-Belmin, V., Wendler, E., Wittmann. F., 1997. Group Report: How Can We Diagnose the Condition of Stone Monuments and Arrive to Suitable Treatment Programs? Saving Our Architectural Heritage: the Conservation of Historic Stone Structures. Eds N. S. Baer, and R. Snethlage. Chichester: J.Wiley and Sons Ltd.

Segurado, J., Acabamentos das Construções. Biblioteca de Instrução Profissional, Livraria Bertrand, Lisboa, $2^{\mathrm{a}}$ Ed., s.d.

Teixeira, G., Belêm, M., 1998. Diálogos de edificação: técnicas tradicionais de construção. 3. ${ }^{\mathrm{a}}$ Edição. Porto: CRAT.

Letellier, R., 2011 Recording, Documentation, Information Management for the Conservation of Heritage Places, Vol. 1 Guiding Principles. The Getty Conservation Institute, Los Angeles, CA.

Eppich, R., 2011 Recording, Documentation, Information Management for the Conservation of Heritage Places, Vol. 2 Illustrated Examples. The Getty Conservation Institute, Los Angeles, CA. 